Research Article

\title{
Investigating Automobile Passengers' Comfort and Safety on Scenic Road Using Sideway Force Coefficient
}

\author{
Ronghua Wang, ${ }^{1}$ Xingliang Liu $\mathbb{D}^{2},{ }^{2}$ and Feijie Han $^{3}$ \\ ${ }^{1}$ College of Architecture and Civil Engineering, Beijing University of Technology, Beijing 100124, China \\ ${ }^{2}$ College of Traffic \& Transportation, Chongqing Jiaotong University, Chongqing 400074, China \\ ${ }^{3}$ CCCC FIRST Highway Consultants Co.,LTD, Xi'an 710064, China \\ Correspondence should be addressed to Xingliang Liu; xingliang1125@outlook.com
}

Received 18 July 2020; Revised 1 September 2020; Accepted 5 October 2020; Published 21 October 2020

Academic Editor: Zhen Leng

Copyright (c) 2020 Ronghua Wang et al. This is an open access article distributed under the Creative Commons Attribution License, which permits unrestricted use, distribution, and reproduction in any medium, provided the original work is properly cited.

\begin{abstract}
To satisfy passengers' experiential demand in scenic roads, a study on passengers' comfort in the aspect of horizontal curve design is stated in this study. A new indicator sideway force coefficient (SFC) describing passengers' comfort is introduced, which differs from lateral acceleration. The mechanism of $S F C$ is provided depending on the dynamic balance condition of the vehicle on horizontal curve and $S F C_{c}$ representing passengers' comfort tolerance limitation is investigated. A large scale naturalistic driving experiments along a park road are conducted, and the $S F C_{c}$ value from naturalistic driving experiments is verified through numerical simulation of 15 horizontal curves from 5 scenic roads from the perspectives of both passengers' comfort and driving safety. The statistical analysis on data collected in field tests indicates that age and gender have no effect on $S F C_{c}$, and the value of $S F C_{c}$ is determined as 0.291 . The corresponding minimum radius limits under $20-60 \mathrm{~km} / \mathrm{h}$ and superelevation $6 \%, 8 \%$, and $10 \%$ are proposed. The numerical simulation denotes, when satisfying the comfort demand of passengers (SFC less than 0.291), the lateral distance path is in a safe range, which could also satisfy the safe driving requirements. Thus, $S F C_{c}$ and minimum radius limits proposed in this study are proved to be credible and appropriate for the curve design of horizontal alignment in scenic roads.
\end{abstract}

\section{Introduction}

Scenic roads refer to the roads inside scenic tourist areas, nature reserves, and parks, only providing services to travelers. In 1968, the "Park Road Standards" [1] was provided to USA Interior Ministry by National Park Service (NPS). This report indicated that scenic road should be distinguished from ordinary state highway for the first time. Moreover, the scenic road design method considering passengers' comfort and experience was also put forward. Usually, the design indicators of scenic road were directly adopted from the criterion for ordinary highway "A Policy on Geometric Design of Highway and Streets" [2]. Although this criterion considered passengers' comfort and experience by introducing traffic quality, a more comprehensive way of promoting passengers' comfort in scenic road, and, to be more specific, an indicator representing passengers' comfort in scenic road is still not put into practice.

The concept of passengers' comfort, or ride comfort, is understood as one aspect of transportation service quality [3]. The essence of passengers' comfort measurement is human perception, defined as "subjective state of well-being or absence of mechanical disturbance in relation to the induced environment" in ISO $5805[4,5]$. This is one of the most challenge topics. Firstly, it is affected by several factors, including age, gender (human factors), temperature, noise, pressure (environmental factors), seat, and workspace (spatial factor) [6]. Secondly, comfort measurement is based on statistic data from large scale personal interviews, which could be a relatively expensive task in terms of human resources $[7,8]$. Thirdly, it was stated in related works that the 
object of evaluating passengers' comfort should be carefully implemented because it might vary among individuals [5].

Previous studies focused on two main aspects related to evaluating passengers' comfort: vehicle dynamics and road geometrics. In aspect of vehicle dynamics, studies related to suspension system which could improve passengers' comfort took the major part, including passive suspension cases with fixed characteristics [9-11] and active suspension cases involving applications of control laws [12-14]. Besides, some researches paid their attention on other aspects in vehicle riding smoothness, for instance, the comfort of passenger seat $[15,16]$, the mechanism of vehicle vibration generation and spreading path $[17,18]$, tolerance limitation of passengers [19], temperature, and noise within the vehicle $[20,21]$.

Another aspect is road geometrics related ones, and also the research topic in this study, interpreted as the geometric design related methods. Among these researches, lateral and longitudinal acceleration were used as indicators to represent the overload on passengers in acceleration/deceleration or turning process. In study by Cafiso and La Cava [22], acceleration was used as the indicator to evaluate the consistency of highway alignment. The safety level of curves and comfort level of various road types in two-lane rural highways were estimated by Lee et al. [23]. Moreover, various acceleration models were developed in road related passengers' comfort studies, including a lateral acceleration model for curved-and-sloped sections [24], a lateral acceleration model for passenger cars considering curve radius as independent variable [25], a longitudinal acceleration model for horizontal curves [26], and a lateral acceleration model for different types of highway and different vehicle [27]. The abovementioned studies basically depended on real road collected data. However, as depicted previously, personal interview is a relatively expensive method. The data collected sometimes seems insufficient to complete all the analysis. Therefore, to compensate this shortage, simulation or calculation data was also used. For instance, simulation speed and acceleration data could be used in analyzing the effects of curve radius, diurnal variation, season on driving comfort [28], passengers' comfort for buses [29], passengers' comfort in mountainous highway [30], and so on.

To sum up, previous studies analyzing passengers' comfort using road geometric indicators mainly choose acceleration to evaluate passengers' comfort, based on both real road data and simulation data. However, it should be noticed that studies listed above rarely focus on scenic road. That is to say, a comprehensive way of promoting passengers' comfort in scenic road is needed. According to related studies [31], the passengers usually feel uncomfortable in curves, owing to the centrifugal force loaded on them. Therefore, lateral acceleration should be considered in evaluating passengers' comfort. However, lateral acceleration does not stand for horizontal overload on passengers [31]. It is not parallel to actual road surface, which means the superelevation is neglected, and lateral acceleration could not fully represent the passengers' overload because human body is vertical to road surface. To solve this critical problem, the indicator sideway force coefficient (SFC) which stands for real overload in a curve is adopted in this study.

As SFC is the key indicator in this study, its derivation process based on dynamic response is firstly provided, and this content also explains why SFC stands for real overload in a curve. To depict passengers' comfort in scenic road using SFC, field tests on over 1000 participants are carried out in 5 different scenic road curves, to determine the value of SFC when passengers feel uncomfortable. Moreover, numerical simulations of 15 horizontal curves from 5 scenic roads are also provided to verify if the SFC representing passengers' comfort would also satisfy the safety demand. In that, a comprehensive way of promoting passengers' comfort in scenic road is developed in this study.

This study is organized as follows. Section 2 depicts the mechanism of SFC by dynamic response. Section 3 states the field test research of passenger comfort and data simulation derived from actual scenic roads. Section 4 provides the determination of maximum value of tolerable SFC and the verification of real scenic road considering passenger comfort and safety.

\section{Dynamic Response-Based SFC}

When driving on scenic road curve, SFC represents driver and passengers' sideway burden, which is the comfort mentioned in Section 1. In aspect of classical dynamic response, SFC is defined as the sideway load on unit vehicle weight. In vehicle's turning process mechanical analysis, the vehicle could be seen as a particle, which is subjected a centrifugal force $F$ on centroid, pointing the direction deviating from the center of this circle, see equation (1). The centrifugal force $F$ will affect the vehicle's operation stability on the curve, which leads to sideway slip and rollover in extreme situation. Therefore, the horizontal superelevation $i_{h}$ is designed in road curve to prevent this situation. The dynamic mechanical balance of the vehicle is shown in Figure 1.

$$
F=\frac{G v^{2}}{g R} .
$$

In Figure 1 and (1), $G$ represents the gravitational force $(\mathrm{N}), \mathrm{v}$ represents the velocity $(\mathrm{m} / \mathrm{s}), R$ represents the radius of this curve, and g represents gravity acceleration $\left(\mathrm{m} / \mathrm{s}^{2}\right)$. When operating on actual scenic road curve, the horizontal part of gravitational force will offset the centrifugal force to some degree, and the rest will be balanced with the friction between tire and road surface, as shown in (2). In the figure depicted above, $\sin \alpha \approx \tan \alpha=i_{h}$. Then, (3) could be obtained.

$$
\begin{gathered}
\left\{\begin{array}{l}
X=F \cos \alpha-G \sin \alpha, \\
Y=F \sin \alpha+G \cos \alpha,
\end{array}\right. \\
X=F-G i_{h}=G\left(\frac{v^{2}}{g R}-i_{h}\right) .
\end{gathered}
$$




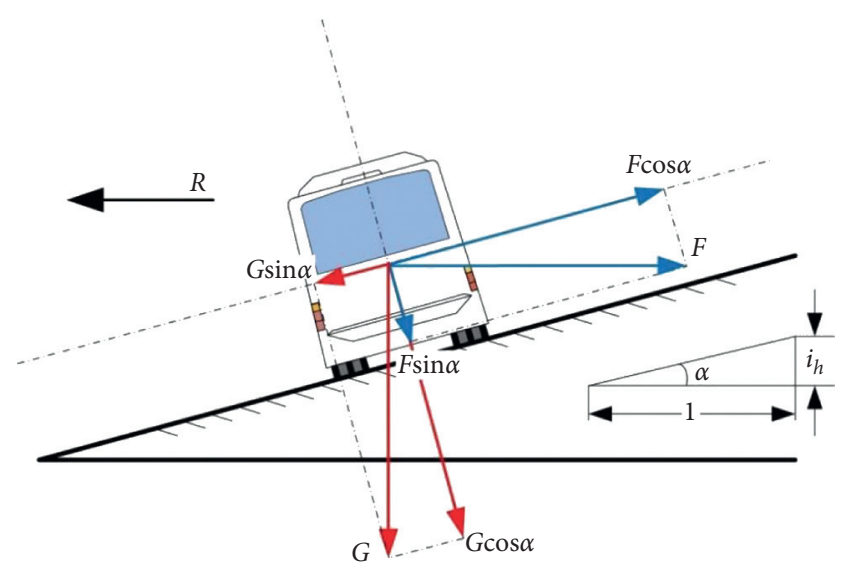

Figure 1: The dynamic mechanical balance of the vehicle on the curve.

In (2) and (3), vertical force $Y(N)$ is the stable element in vehicle operation, and sideway force $X(N)$ is the unstable element. However, the value of sideway force could not represent the stability of vehicles with different weight. For example, a sideway force of $5000 \mathrm{~N}$ on passenger car might lead to rollover accident, but this might not happen on a heavy vehicle. Thus, SFC represents the sideway load on unit vehicle weight is defined in the following.

$$
S F C=\frac{x}{G}=\frac{v^{2}}{g R}-i_{h}
$$

The relationship among velocity, radius of the curve, horizontal superelevation, and SFC is obtained in (4) based on the method of dynamic response. According to (4), if velocity was controlled the same, SFC will be inversely proportional to $R$, as shown in Figure 2. In actual scenic road design, there exists a $R_{0}$ where SFC equals 0 . It means that when the radius of a curve could be larger than $R_{0}$, it is unnecessary to set a superelevation $i_{h}$, and $R_{0}$ could be seen as the upper boundary of curve design in some degree. Relatively, there exists a lower radius boundary $R_{u}$ which is related to velocity and terrain. However, as mentioned in Section 1, SFC could represent the driver and passengers' comfort, and human physiological tolerance is limited, which could be interpreted as $S F C_{c}$ in this situation. The element of tourist experience is not taken into consideration in scenic road design, and if the situation $S F C_{c}>S F C_{u}$ depicted in Figure 2 exists, the scenic road will not satisfy the passengers' demand.

Therefore, the SFC considering the passengers' comfort will be studied in the next part. To further check if a current used scenic road curve radius satisfied the passengers' comfort demand, (5) could be used:

$$
S F C_{c}=\frac{v^{2}}{127 R_{u}}-i_{h}
$$

\section{Field Tests and Data Simulation}

In Section 2, the relationship between SFC and curve radius has been found based on dynamic response analysis. Besides, according to the description upon SFC and the passengers'

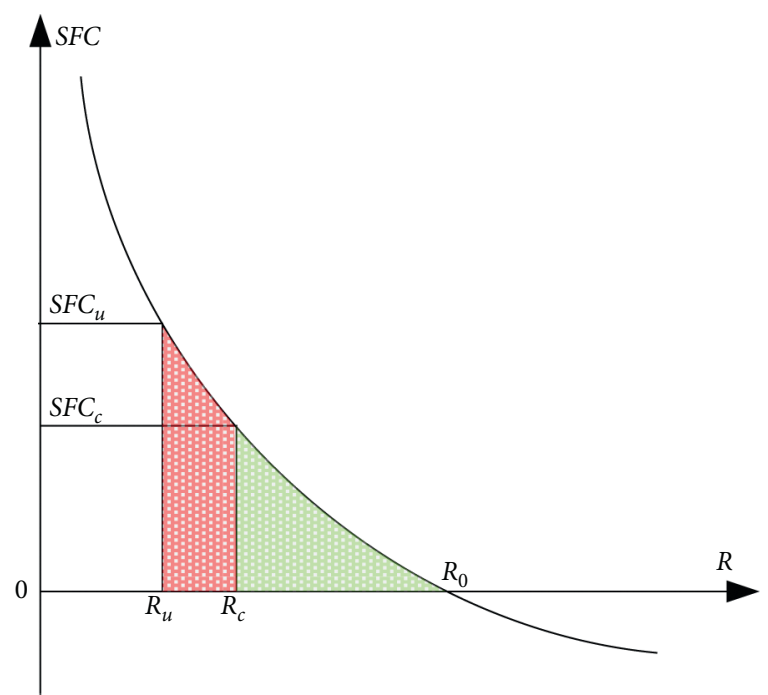

FIgUre 2: The relationship between $S F C$ and $R$ in scenic road curve design.

comfort in Section 1, it is reasonable to assume that there would be a limited value $S F C_{c}$, which represents the physiological tolerance of the passengers while operating on a scenic road curve. In that, to find the accurate value of $S F C_{c}$, field tests should be carried out, owing to that human feeling is very complex and inaccurate to be theoretically modeled. Once $S F C_{c}$ is found, superelevation values and corresponding minimum radius limits $R_{c}$ considering passengers' comfort, under different design speeds, could be obtained using (4). Besides, the objective of studying $S F C_{c}$ based on passengers' comfort is to develop scenic road design methods. Therefore, a data simulation is adopted to check if the radius $R_{c}$ corresponding to $S F C_{c}$ would satisfy the safety principle.

3.1. $\mathrm{SFC}_{c}$ Field Tests. According to the statement in related reference [32], human has the full ability to identify the boundary of comfortable feeling and uncomfortable feeling. But there is no evidence which shows the boundary will vary among different individuals. Besides, it is known from (4) that SFC is proportional to the vehicle's operation velocity when driving on a specific scenic road curve. Therefore, driving velocity could be used as a tool to find $S F C_{c}$. In current scenic road design criterion, the speed limit is $60 \mathrm{~km} / \mathrm{h}$, and the curve radius limitation is $150 \mathrm{~m}$. Based on the contents mentioned above, the field tests should follow the principles given below:

(i) The group of participants should cover people with different gender and age. The amount of men and women should be roughly equal, and the amount of the elder should process the minority, considering the actual passengers situation in scenic spot.

(ii) Different bending speed should be adopted to find $S F C_{c}$ in specific curves, and curves with different radius should be also studied. 
(iii) During the field test, the driving velocity and radius adopted should less than the limitations in current scenic road design criterion.

Before planning detailed field test scheme, five scenic road curves were chosen in Nanhu Park, Xi'an, China, where horizontal alignment of scenic road is complex, containing several ideal test curves, while the vertical alignment is simple, without many slopes, which decreases the difficulty of carrying out this field test. Furthermore, the pavement material in this scenic road is consistent, and there are also no obstacles such as deceleration zone in this road. Positions of road curves are shown in Figure 3; radius and other information of these curves are provided in Table 1.

In each curve, participants were randomly chosen, following the principle mentioned above. In one single test group, the participant was blindfolded, because passengers under this condition have more sensitive perception on centripetal force [21]. The test vehicle (Volkswagen Bora $2008,110 \mathrm{kw} / 250 \mathrm{~N} \cdot \mathrm{m}$ ) traveled through the curve with stable velocity varied from $10 \mathrm{~km} / \mathrm{h}-60 \mathrm{~km} / \mathrm{h}$, with the step of $5 \mathrm{~km} / \mathrm{h}$. A self-designed instrument was used to measure the real-time SFC. This instrument contains a MPU6050 three-axis gyroscope to percept the lateral acceleration, an AT89S52 control unit embedded the program calculating SFC using method provided in Section 2 and a LCD screen to display the value of SFC. There is also a specific button to start the program. Whenever participants felt unable to tolerate sideway load, they would press the button on this instrument for once to record the value of SFC in this single test as $S F C_{c}$. Instrument used in this study and record of field experiment is shown in Figure 4.

Field tests were carried out for 1056 groups in 85 days, which means 1056 participants were investigated. Among them, 487 were males, 569 were females, and 447 were $18-40$ years old (interpreted as the youth), 575 were $41-65$ (the middle-aged), and 34 were above 66 (the elder) [33-35]. It should be noticed that not all the test results were available. Though the participants were blindfolded to strengthen their perception, not all the influencing factors could be excluded. Therefore, the participants were asked to answer two questions after the tests. (1) Did they clearly percept the uncomfortable feeling brought by centripetal force? (2) Did they press the button at the best opportunity? Only answers of these two questions were both "yes"; the participant could be regarded as valid. Detailed information could be seen in Table 2 .

3.2. Data Simulation. As depicted in the first paragraph in this section, the objective of this paper is to improve the design method of scenic road curve based on the passengers' comfort demand. Therefore, the current used scenic road should be verified in both comfort and safety principle. According to road design criterion, the current used scenic road curve radius varied from $10 \mathrm{~m}$ to $110 \mathrm{~m}$, and the speed limit varied from $20 \mathrm{~km} / \mathrm{h}$ to $60 \mathrm{~km} / \mathrm{h}$. In common situation, a specific scenic spot will adopt a consistent speed limit which largely depends on the terrain and will also affect the chosen curve radius. Thus, it is difficult to launch a complete field experiment in one single scenic spot because it does not contain enough curve samples.

To make up the shortage mentioned above, data simulations were adopted based on CarSim platform, which provides sufficient vehicle models, driver models, road models and parameters related to driving environment, vehicle control, and so on. The first step is to build road simulation model. Five real scenic road sections were chosen to form the background of simulation models. The basic information on these road sections are shown in Table 3.

Based on the investigation of the five background scenic spots, it could be concluded that two typical vehicle types are commonly used, large gasoline consuming passenger vehicle, and small electric power passenger vehicle. The operation velocity of large passenger vehicle varies from $30 \mathrm{~km} /$ $\mathrm{h}-60 \mathrm{~km} / \mathrm{h}$, which could be found in section $C_{2}, C_{3}, C_{4}$, and $C_{5}$. The operation velocity of small passenger vehicle varies from $20 \mathrm{~km} / \mathrm{h}$ to $30 \mathrm{~km} / \mathrm{h}$, which could be found in sections $C_{1}$ and $C_{2}$. With the detailed information collected, the models of two typical vehicle types were built up, shown in Tables 4 and 5 .

To complete the data simulation model, the driver's microscopic control model should be built. According to theory of driver's path preview, the total preview length of $100 \mathrm{~m}$ was adopted, and the preview interval was set to $4 \mathrm{~m}$. Parameters of longitudinal maximum acceleration (LMA), longitudinal maximum deceleration (LMD), and horizontal maximum acceleration (HMA) were defined in Figure 5 based on driver's path preview theory.

\section{Results}

In this part, data from field test were analyzed using statistical methods and hypothetical test. The limited value $S F C_{c}$, which represents the physiological tolerance of the passengers while operating on a scenic road section, was found. Besides, in data simulation, 15 scenic road sections were verified based on safety and comfort principle.

4.1. Determination of $\mathrm{SFC}_{c}$. As depicted in previous work [36], people have full ability to identify the boundary between comfortable feeling and uncomfortable feeling. However, it is still unknown if the boundary $\left(S_{F C}\right)$ would vary among different individuals. In field tests, 1056 subjects were investigated in 5 curves to observe the values of their $S F C_{c}$. In the test group, age and gender could be directly used as two independent variables to study $S F C_{c}$. Therefore, the participants in each curve could be divided into younger group (age 18-40) and elder group (age 41-65), and it could also divided into male group and female group.

In curve 1 (radius $=130 \mathrm{~m}$, length $=246 \mathrm{~m}$, gradient $=0 \%), 152$ subjects were tested, and only 22 subjects recorded their $S F C_{c}$. The rest subjects did not have any uncomfortable feeling during the test process. However, according to the road design criterion, the speed limit in scenic spots is $60 \mathrm{~km} / \mathrm{h}$. Therefore, the results in curve 1 were excluded. 


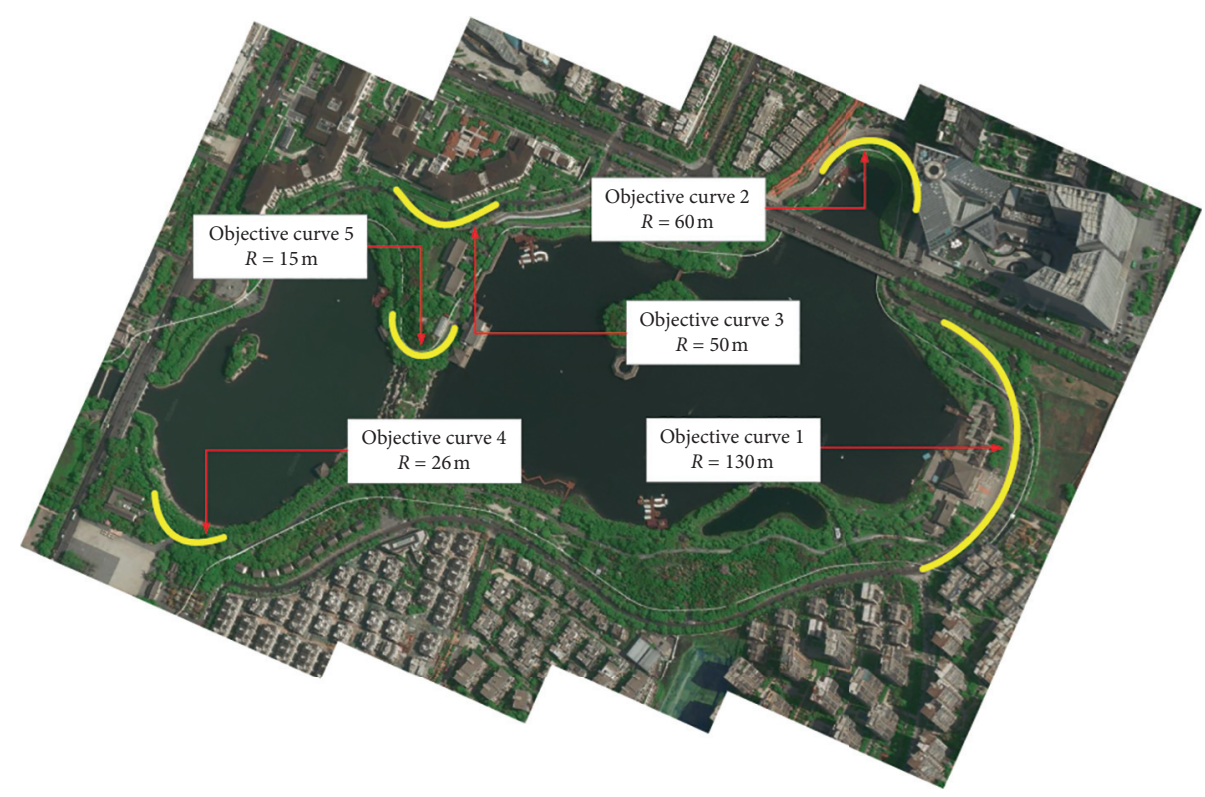

Figure 3: Field tests positions in Nanhu Park, Xi'an, China.

TABLE 1: Radius and related information of horizontal curves.

\begin{tabular}{lccc}
\hline Number & Radius $(\mathrm{m})$ & Length $(\mathrm{m})$ & Gradient $(\%)$ \\
\hline 1 & 130 & 246 & 0 \\
2 & 60 & 182 & 1 \\
3 & 50 & 134 & 1.5 \\
4 & 26 & 52 & 0.5 \\
5 & 15 & 22 & 0 \\
\hline
\end{tabular}

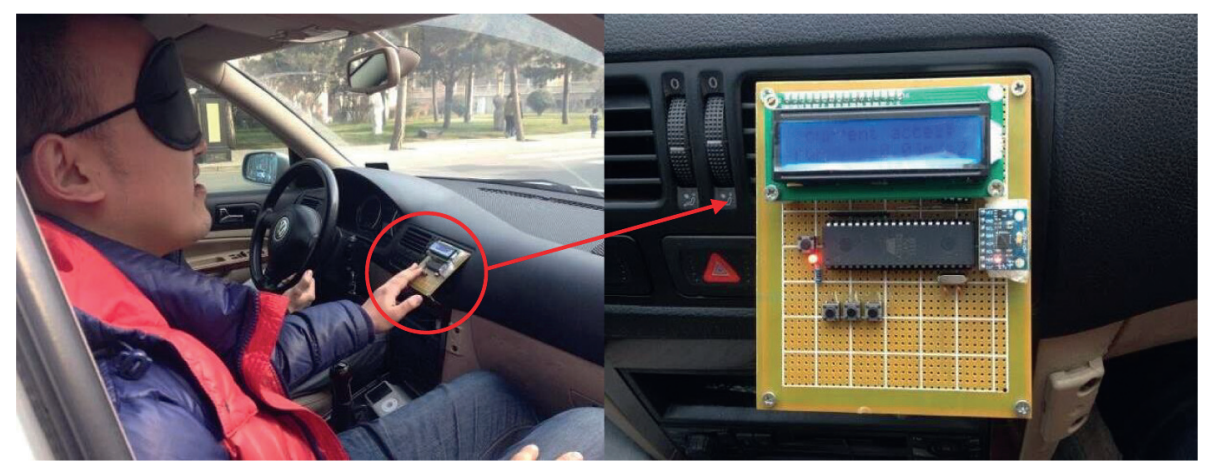

FIgURE 4: Instrument used in this study and record of field experiment.

TABLE 2: Statistical description information.

\begin{tabular}{|c|c|c|c|c|c|c|c|c|c|c|}
\hline \multirow{2}{*}{ Group division } & \multicolumn{2}{|c|}{ Test curve 1} & \multicolumn{2}{|c|}{ Test curve 2} & \multicolumn{2}{|c|}{ Test curve 3} & \multicolumn{2}{|c|}{ Test curve 4} & \multicolumn{2}{|c|}{ Test curve 5} \\
\hline & Total & Excluded & Total & Excluded & Total & Excluded & Total & Excluded & Total & Excluded \\
\hline \multicolumn{11}{|l|}{ Gender } \\
\hline Male & 82 & 7 & 114 & 6 & 109 & 5 & 108 & 6 & 74 & 11 \\
\hline Female & 70 & 4 & 140 & 4 & 139 & 7 & 141 & 8 & 79 & 4 \\
\hline \multicolumn{11}{|l|}{ Age } \\
\hline $18-40$ & 65 & 5 & 101 & 3 & 96 & 1 & 98 & 2 & 87 & 5 \\
\hline $41-65$ & 80 & 3 & 147 & 1 & 144 & 3 & 143 & 4 & 61 & 5 \\
\hline Above 66 & 7 & 2 & 6 & 1 & 8 & 1 & 8 & 2 & 5 & 0 \\
\hline
\end{tabular}


TABle 3: Basic information of background road sections.

\begin{tabular}{|c|c|c|c|c|c|c|}
\hline Number & $\begin{array}{l}\text { Background } \\
\text { scenic spot }\end{array}$ & $\begin{array}{l}\text { Section } \\
\text { number }\end{array}$ & $\begin{array}{c}\text { Curve } \\
\text { radius (m) }\end{array}$ & $\begin{array}{l}\text { Road section } \\
\text { length }(\mathrm{m})\end{array}$ & $\begin{array}{c}\text { Speed limit } \\
(\mathrm{km} / \mathrm{h})\end{array}$ & $\begin{array}{c}\text { Superelevation } \\
(\%)\end{array}$ \\
\hline 1 & \multirow{3}{*}{ Cuihua mountain area, China } & \multirow{3}{*}{$C_{1}$} & 8 & \multirow{3}{*}{323.9} & \multirow{3}{*}{20} & 10 \\
\hline 2 & & & 17 & & & 10 \\
\hline 3 & & & 20 & & & 10 \\
\hline 4 & \multirow{3}{*}{ Taibai mountain area, China } & \multirow{3}{*}{$C_{2}$} & 20 & \multirow{3}{*}{570.5} & \multirow{3}{*}{30} & 8 \\
\hline 5 & & & 32 & & & 8 \\
\hline 6 & & & 50 & & & 4 \\
\hline 7 & \multirow{3}{*}{ Taibai mountain area, China } & \multirow{3}{*}{$C_{3}$} & 35 & \multirow{3}{*}{764.4} & \multirow{3}{*}{40} & 10 \\
\hline 8 & & & 55 & & & 6 \\
\hline 9 & & & 75 & & & 6 \\
\hline 10 & \multirow{3}{*}{ Nalati prairie, China } & \multirow{3}{*}{$C_{4}$} & 55 & \multirow{3}{*}{798.4} & \multirow{3}{*}{50} & 8 \\
\hline 11 & & & 55 & & & 8 \\
\hline 12 & & & 75 & & & 4 \\
\hline 13 & \multirow{3}{*}{ Nalati prairie, China } & \multirow{3}{*}{$C_{5}$} & 75 & \multirow{3}{*}{1049.2} & \multirow{3}{*}{60} & 10 \\
\hline 14 & & & 90 & & & 10 \\
\hline 15 & & & 110 & & & 10 \\
\hline
\end{tabular}

TABLE 4: Model of large gasoline consuming passenger vehicle.

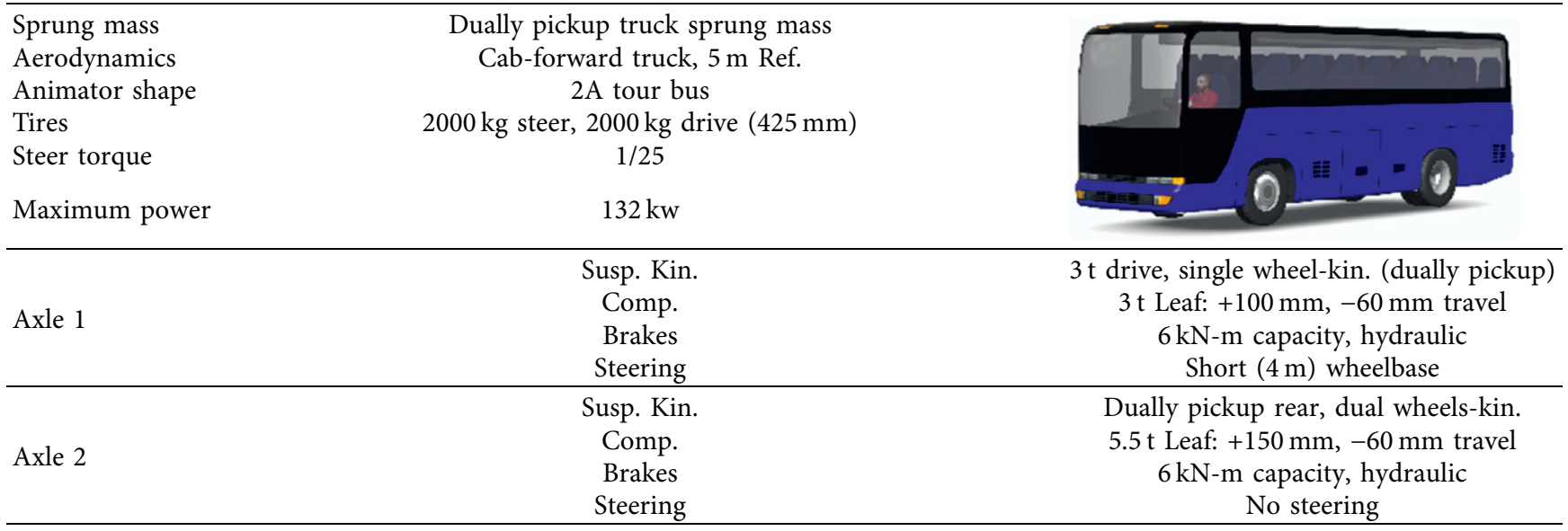

TABLE 5: Model of small electric power passenger vehicle.

\begin{tabular}{lcc}
\hline $\begin{array}{l}\text { Sprung mass } \\
\text { Aerodynamics }\end{array}$ & C-class, hatchback sprung mass \\
Animator shape & C-class, hatchback aero \\
Rear drive torque & Large European van \\
Maximum power & 3800 \\
Brake system & $28.5 \mathrm{kw}$ \\
Steering system & 4 -wheel, w/o ABS \\
& 4-wheel, power, R\&P & C-class, hatchback-front suspension \\
Front & Front kinematics & C-class, hatchback-front comp \\
& Front compliance & $205 / 55 \mathrm{R} 16$ \\
& Right-front tire & $205 / 55 \mathrm{R} 16$ \\
Left-front tire & C-class, hatchback, rear suspension \\
Rear & Rear kinematics & C-class, hatchback, rear comp \\
& Rear compliance & $205 / 55 \mathrm{R} 16$ \\
& Right-rear tire & $205 / 55 \mathrm{R} 16$ \\
\hline
\end{tabular}

The results of younger group and elder group in curves 2-5 are shown in Figure 6. In figures given below, the horizontal axis represents the serial number of participants, and the vertical axis represents the $S F C_{c}$ observed in field test. The blue polyline shows the results of younger group, and the red polyline shows the results of elder group. Besides, the average value of $S F C_{c}$ in each group was also provided. 


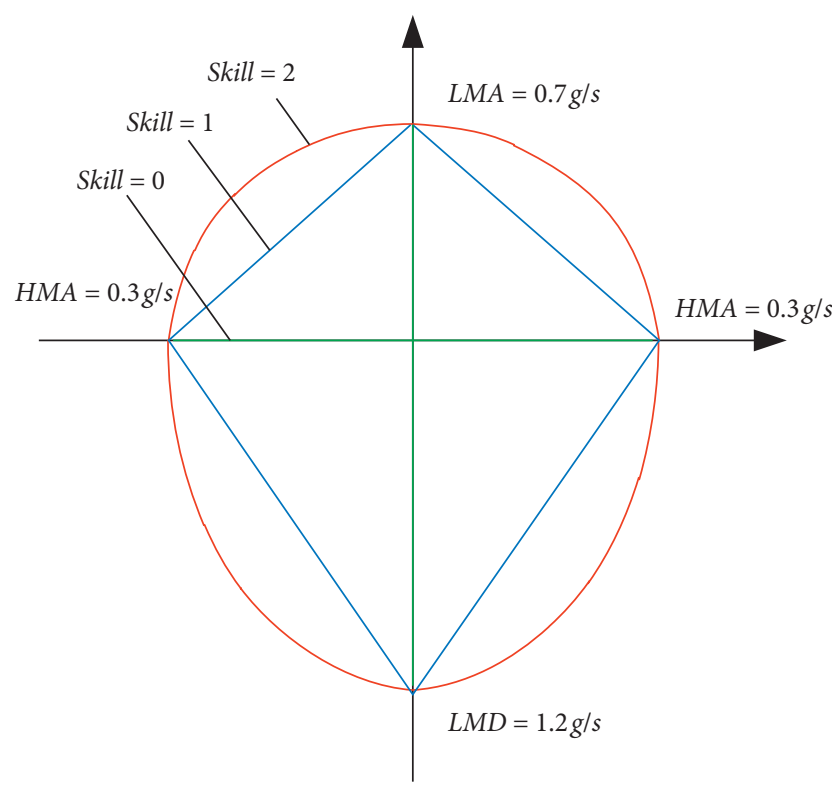

Figure 5: The driver's microscopic control model.

In Figure 6, it is not complex to find out that observed $S F C_{c}$ in each group of section 2-5 were scattered around a certain value, which is the average value of this group. It means that the boundary between comfortable feeling and uncomfortable feeling of different individual varies in a relatively small range, and the distribution is also random. In Figure 6, the average $S F C_{c}$ values of younger groups in curve $2-5$ are $0.2903,0.2910,0.2905$, and 0.2866 , and the average $S_{F C}$ values of elder groups in curve $2-5$ are $0.2910,0.2910$, 0.2886 , and 0.2954 . Depending on the values given above, it is reasonable to account that $S F C_{c}$ of the younger and the elder are the same. To further prove this point, the method of hypothetical test is used. In field test, each subject is relatively independent, and the sample obeys normal distribution. Using Levene's test to check if the sample variance is homogeneous, the significance equals to 0.208 which larger than 0.05 , which shows that the sample variance is homogeneous. Further, using $T$-test to check if there was significant difference between $S F C_{c}$ of the younger and the elder, the significance equals 0.628 which is larger than 0.05 , which proved the point given above.

The results of male group and female group in curve 2-5 are shown in Figure 7. The information expressed by Figure 7 is the same of Figure 6.

Figure 7 shows mainly the same characters of Figure 6. Overall speaking, $S F C_{c}$ in each group of curve 2-5 was scattered around the average value of this group. It also proved that the boundary between comfortable feeling and uncomfortable feeling of different individual remains the same. In Figure 7, the average $S F C_{c}$ values of male groups in curve $2-5$ are $0.2907,0.2941,0.2910$, and 0.2919 , and the average $S_{F C}$ values of female groups in curve 2-5 are $0.2945,0.2917,0.2868$, and 0.2919 . Also, the method of hypothetical test is used. In field test, each subject is relatively independent, and the sample obeys normal distribution. Using Levene's test to check if the sample variance is homogeneous, the significance equals 0.792 which is larger than 0.05 , which shows that the sample variance is homogeneous. Further, using $T$-test to check if there was significant difference between $S F C_{c}$ of the male and the female, the significance equals 0.210 which is larger than 0.05 , proving the point given above.

Based on the analysis given above, it could be concluded that the boundary between comfortable feeling and uncomfortable feeling of different individual remains the same, which could be represented by a certain value $S F C_{c}$, equals 0.291 . Restricted by terrain condition, ecological and environment protection and larger superelevation values were considered and the corresponding minimum radii limits under different design speeds were given using (4) as shown in Table 6.

4.2. Comfort and Driving Safety Verification of Scenic Road Curve Design. The objective of this paper is to promote the design method of scenic road curve based on the passengers' comfort demand. To meet this objective, 5 simulation models were built based on real background scenic road sections, including 15 road curves, depicted in Table 3. In Section 4.1, the value of $S F C_{c}$ was determined, which equals 0.291 . This provides a basis to check if current scenic road curves satisfied the passengers' comfort demand. Besides, it is also important to examine if the curve radius satisfied the requirement of safe driving. Based on the Vehicle Maneuverability Objective Evaluation System (VMOES) developed by Guo [32], it is known that the parameter Lateral Distance to Path (LDP) should be less than $0.3 \mathrm{~m}$, while the vehicle is operating on a certain curve.

The simulation model of Section 1 consists of three small reverse curves, whose radiuses are $8 \mathrm{~m}, 17 \mathrm{~m}$, and $20 \mathrm{~m}$, and detailed information could be found in Table 3 . The simulation results of Section 1 are provided in Figure 8 .

In Figure 8(a), supervised LDP in each small curve falls in $[-0.3 \mathrm{~m}, 0.3 \mathrm{~m}]$, which means the requirement of safe driving is satisfied. In Figure 8(b), supervised SFC in small curve 2 and 3 falls in [-0.291, 0.291]; however, SFC in small curve 1 whose radius equals $8 \mathrm{~m}$ is -0.310 , which exceeds the bottom boundary. This means small curve 1 did not satisfy the passengers' comfort demand.

The simulation model of Section 2 also consists of three small reverse curves, whose radiuses are $20 \mathrm{~m}, 32 \mathrm{~m}$, and $50 \mathrm{~m}$. In Section 2, large gasoline consuming passenger vehicle and small electric power passenger vehicle could both be found. The simulation results of Section 2 are provided in Figure 9 shown below.

In Figure 9(a), supervised LDP in each small curve of both vehicle types falls in $[-0.3 \mathrm{~m}, 0.3 \mathrm{~m}]$, which means the requirement of safe driving is satisfied. In Figure 9(b), supervised SFC of both vehicle types in small curve 2 and 3 falls in $[-0.291,0.291]$; however, SFC of both vehicle types in small curve 1 whose radius equal to $20 \mathrm{~m}$ is -0.312 and -0.314 , which exceed the bottom boundary. This means small curve 1 did not satisfy the passengers' comfort demand.

The simulation model of Section 3 consists of three small reverse curves, whose radiuses are $35 \mathrm{~m}, 55 \mathrm{~m}$, and $75 \mathrm{~m}$. In Section 3, only large gasoline consuming passenger vehicle 


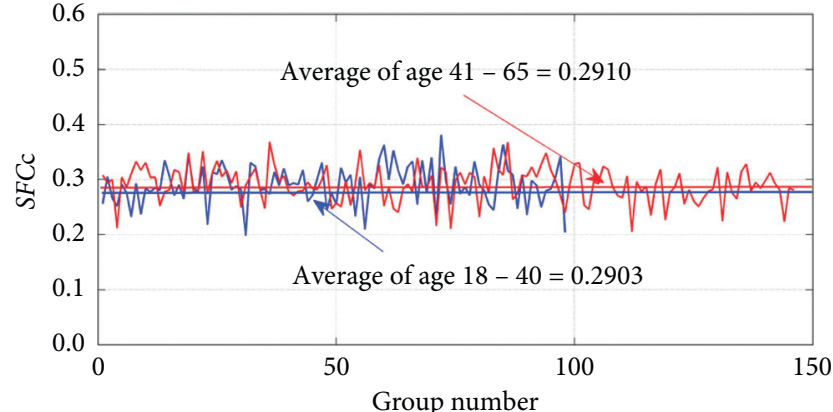

- Age $18-40$

- Age $41-65$

(a)

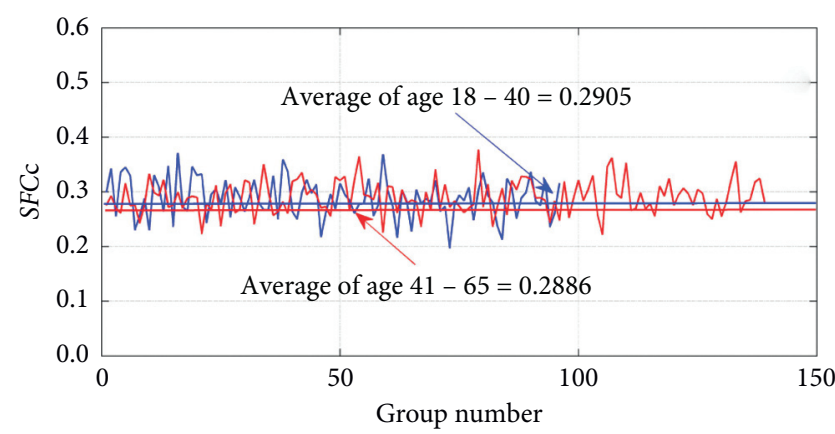

- Age $18-40$

- Age $41-65$

(c)

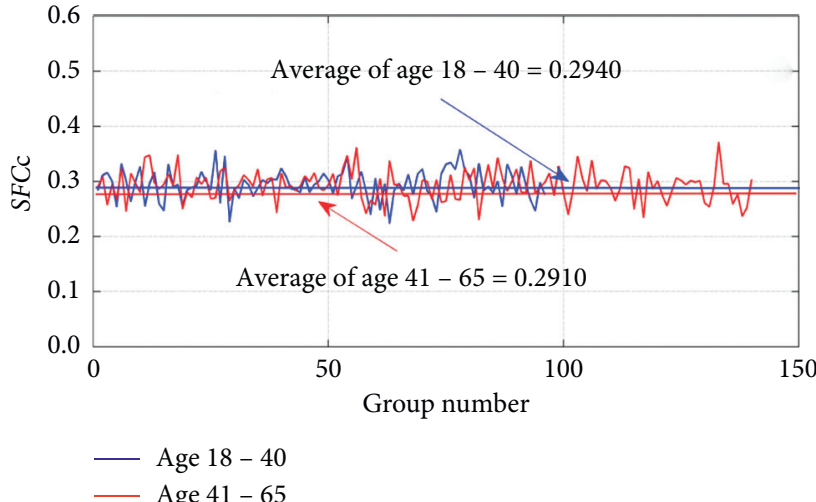

(b)

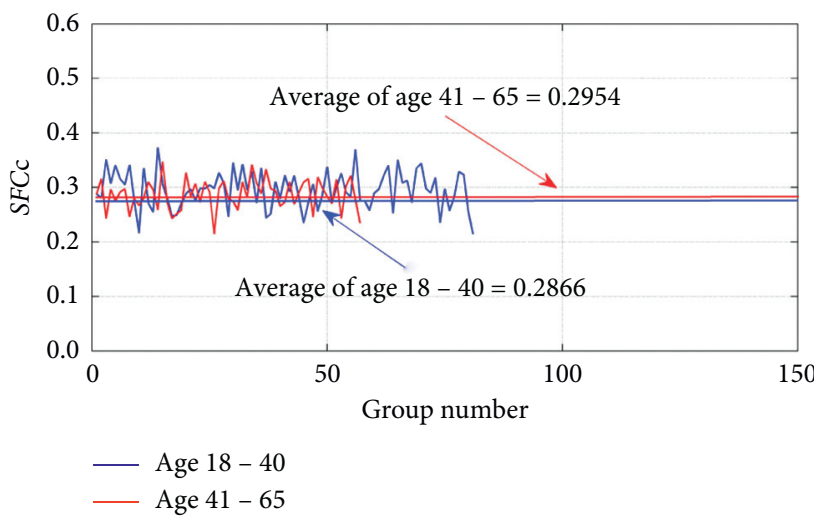

(d)

Figure 6: The $S F C_{c}$ of different age group. (a) Section 2. (b) Section 3. (c) Section 4. (d) Section 5.

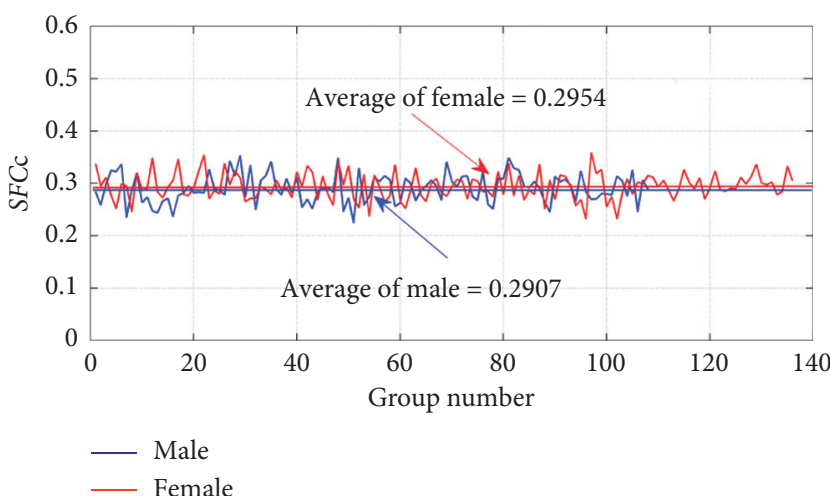

(a)

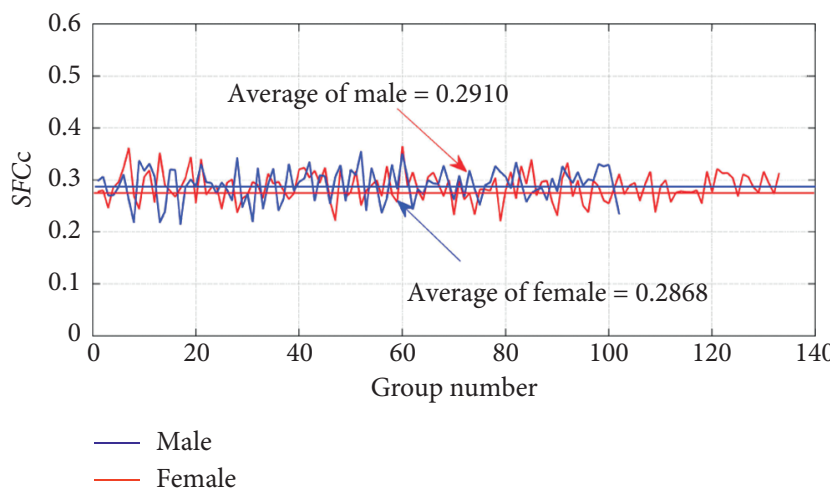

(c)

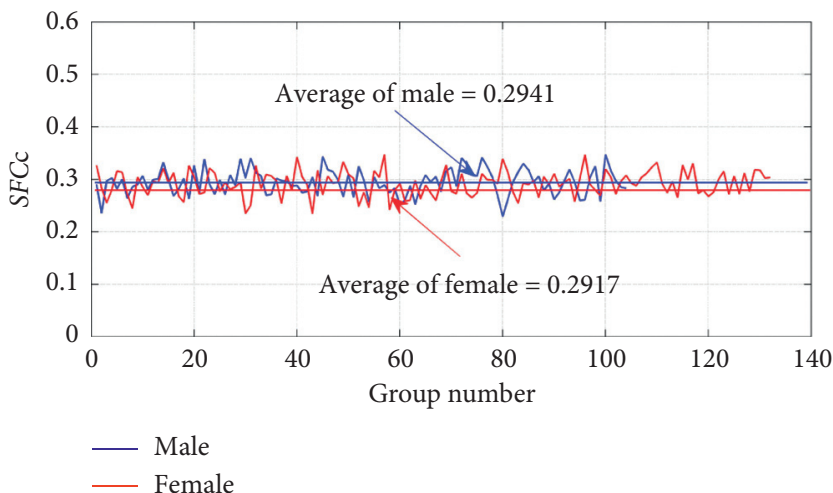

(b)

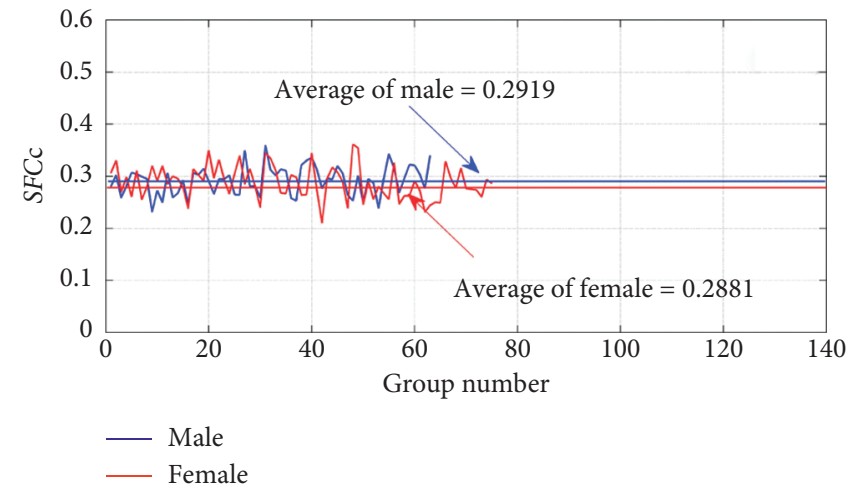

(d)

Figure 7: The $S F C_{c}$ of different gender group. (a) Section 2. (b) Section 3. (c) Section 4. (d) Section 5. 
TABLE 6: Minimum radii limit for design superelevation and design speeds.

\begin{tabular}{lcccccc}
\hline Design speed $(\mathrm{km} / \mathrm{h})$ & & 60 & 50 & 40 & 30 & 20 \\
\hline \multirow{3}{*}{ Minimum radii limit $(\mathrm{m})$} & $i_{h}=10 \%$ & 75 & 55 & 35 & 20 & 10 \\
& $i_{h}=8 \%$ & 80 & 55 & 35 & 20 & 10 \\
& $i_{h}=6 \%$ & 85 & 60 & 40 & 20 & 10 \\
\hline
\end{tabular}

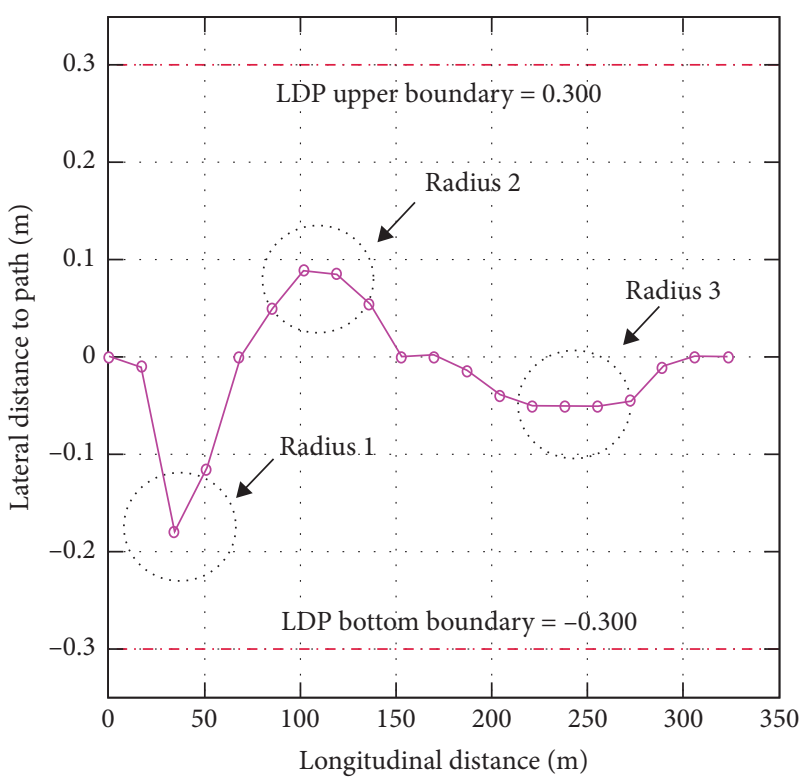

- LDP in section1

(a)

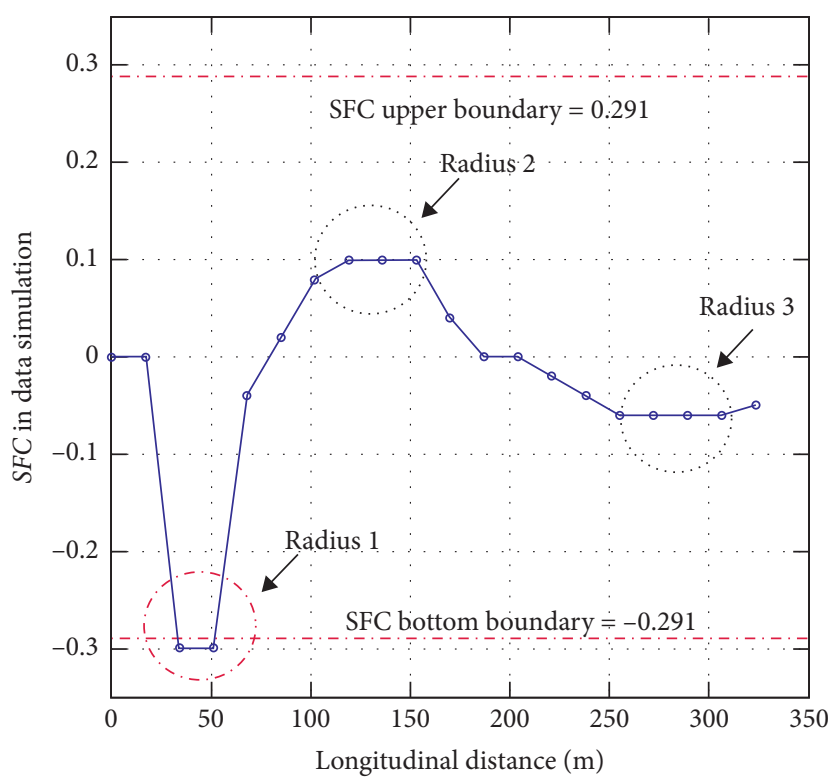

SFC in section 1

FIgure 8: The simulation results of Section 1. (a) Lateral Distance Path Change Trend. (b) SFC Change Trend.

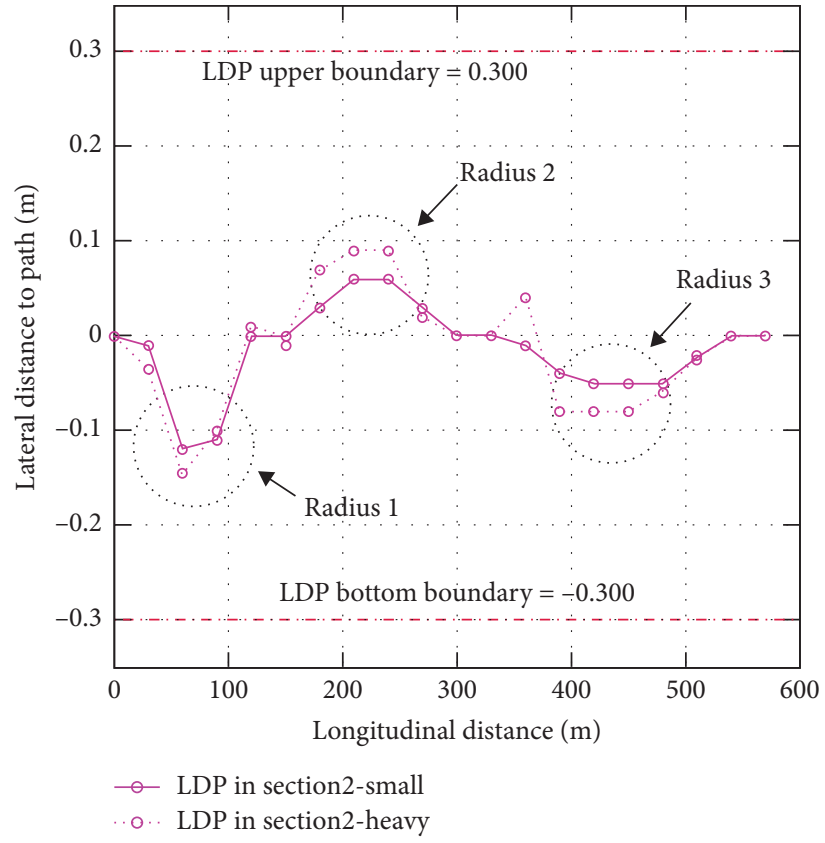

(a)

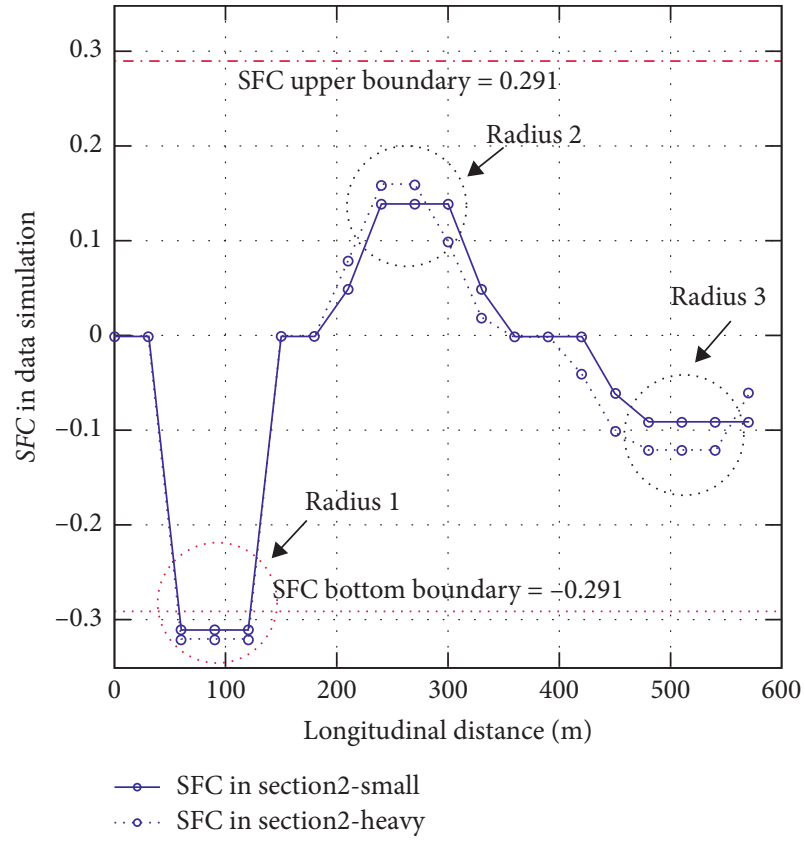

(b)

Figure 9: The simulation results of Section 2. (a) Lateral Distance Path Change Trend. (b) SFC Change Trend. 


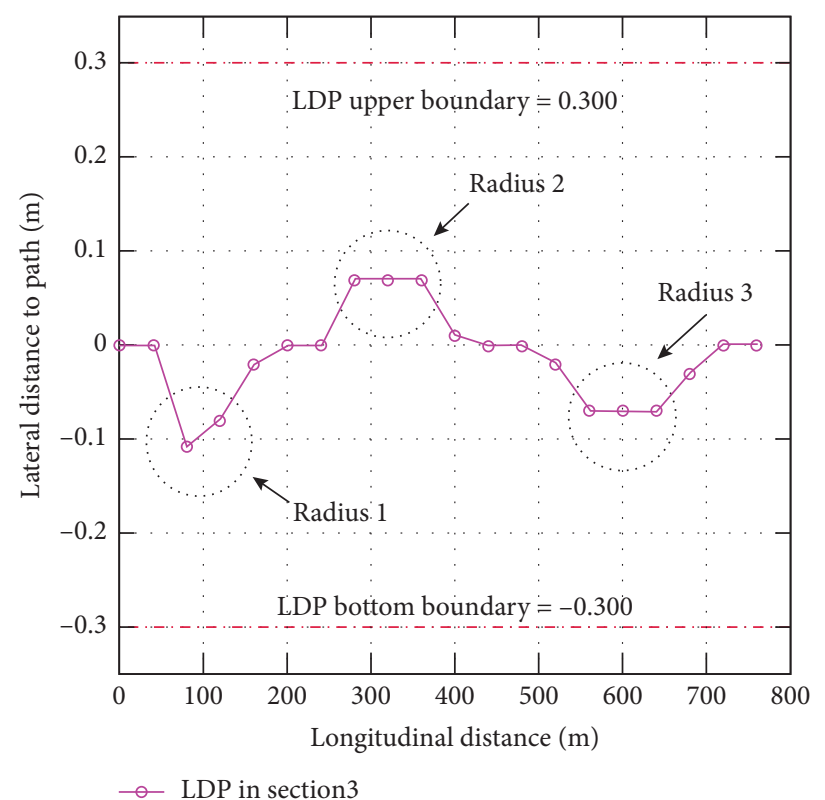

(a)

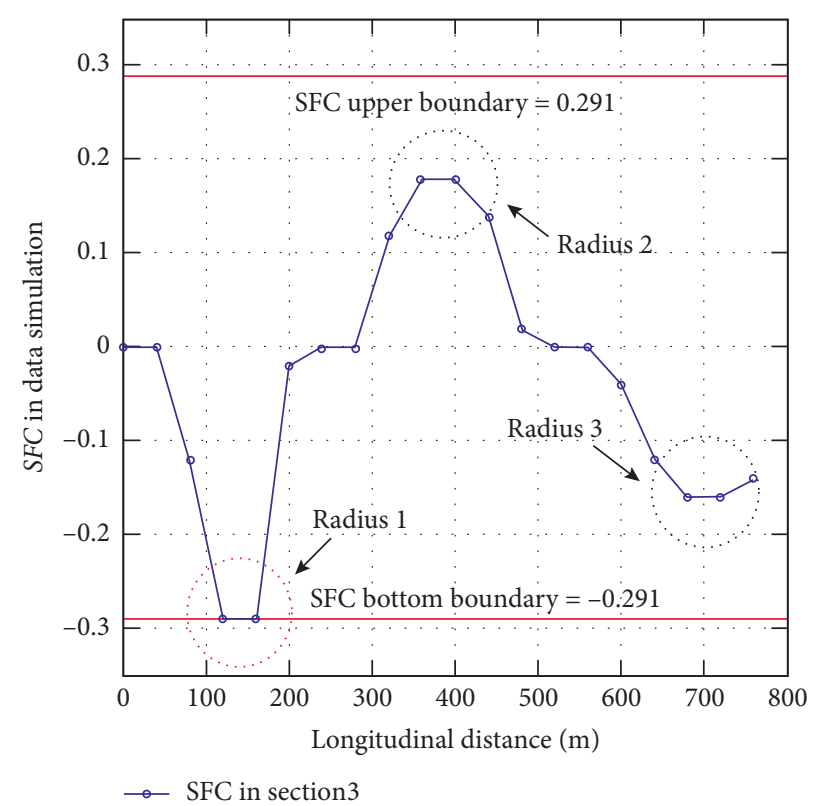

(b)

Figure 10: The simulation results of section 3. (a) Lateral Distance Path Change Trend. (b) SFC Change Trend.

could be found. The simulation results of Section 3 are provided in Figure 10.

In Figure 10(a), supervised LDP in each small curve falls in $[-0.3 \mathrm{~m}, 0.3 \mathrm{~m}]$, which means the requirement of safe driving is satisfied. In Figure 10(b), supervised SFC in small curve 2 and 3 falls in [-0.291, 0.291]; however, SFC in small curve 1 whose radius equals $35 \mathrm{~m}$ is -0.291 , which equals the bottom boundary. This means small curve 1 did not satisfy the passengers' comfort demand.

The simulation model of Section 4 consists of three small reverse curves, whose radiuses are $55 \mathrm{~m}, 55 \mathrm{~m}$, and $75 \mathrm{~m}$. In Section 4, only large gasoline consuming passenger vehicle could be found. The simulation results of section 4 are provided in Figure 11 shown below.

In Figure 11(a), supervised LDP in each small curve falls in $[-0.3 \mathrm{~m}, 0.3 \mathrm{~m}]$, which means the requirement of safe driving is satisfied. In Figure 11(b), supervised SFC in small curve 3 falls in $[-0.291,0.291]$; however, SFC in small curve 1 and 2 whose radius equal to $55 \mathrm{~m}$ and $75 \mathrm{~m}$ is -0.305 and 0.300 , which exceed the bottom boundary and upper boundary, respectively. This means small curve 1 and 2 did not satisfy the passengers' comfort demand.

The simulation model of Section 5 consists of three small reverse curves, whose radiuses are $75 \mathrm{~m}, 90 \mathrm{~m}$, and $110 \mathrm{~m}$. The simulation results of Section 5 are provided in Figure 12.

In Figure 12(a), supervised LDP in each small curve falls in $[-0.3 \mathrm{~m}, 0.3 \mathrm{~m}]$, which means the requirement of safe driving is satisfied. In Figure 12(b), supervised SFC in small curve 2 and 3 falls in [-0.291, 0.291]; however, SFC in small curve 1 whose radius equals $75 \mathrm{~m}$ is -0.300 , which exceeds the bottom boundary. This means small curve 1 did not satisfy the passengers' comfort demand.

To further study the contents given above, some detailed information could be discovered. Considering the supervised LFD as a whole, it is easy to find that LFD is a loose criterion. In curves with small radius, the volatilities of LFDs are obvious; however, they basically fall in $[-0.15 \mathrm{~m}$, $0.15 \mathrm{~m}$ ], far less than the limitation. Besides, comparing the supervised SFC in each curve, when the operation velocity is stationary, the situation of dissatisfying the passengers' comfort demand only exists in curve with relatively small radius. Therefore, in the process of scenic road curve design, when the operation velocity is settled, minimum radius should be determined considering $S F C_{c}$.

\section{Discussion}

As depicted in Section 1, factors of age, gender, temperature, noise, pressure, seat, and workspace have influence on passengers' comfort [6]. In this paper, interior environment was controlled by using the same test vehicle. Thus, factors of age and gender became the major consideration. From the results in Section 4.1,SFC of younger group varies in [0.2866, 0.2910], and $S F C_{c}$ of elder group varies in [0.2886, 0.2954]. $S F C_{c}$ of male group varies in [0.2907, 0.2941], and $S F C_{c}$ of female group varies in [0.2868, 0.2945]. Overall, younger group distribution interval is about $1.1 \%$ less than elder group, and male group distribution interval is about $0.7 \%$ larger than female group. Directly from the data, there is little difference in age groups and gender groups, also proved in Section 4.1 using $T$-test. This indicates that factors of age and gender basically have no influence on passengers' comfort, which is different from traditional result [6]. Considering the large-scale real road samples obtained in this study, the result is credible.

Further, Section 1 states that SFC is different from lateral acceleration. From mechanism of SFC in Figure 1, the gap between SFC and lateral acceleration will not be 


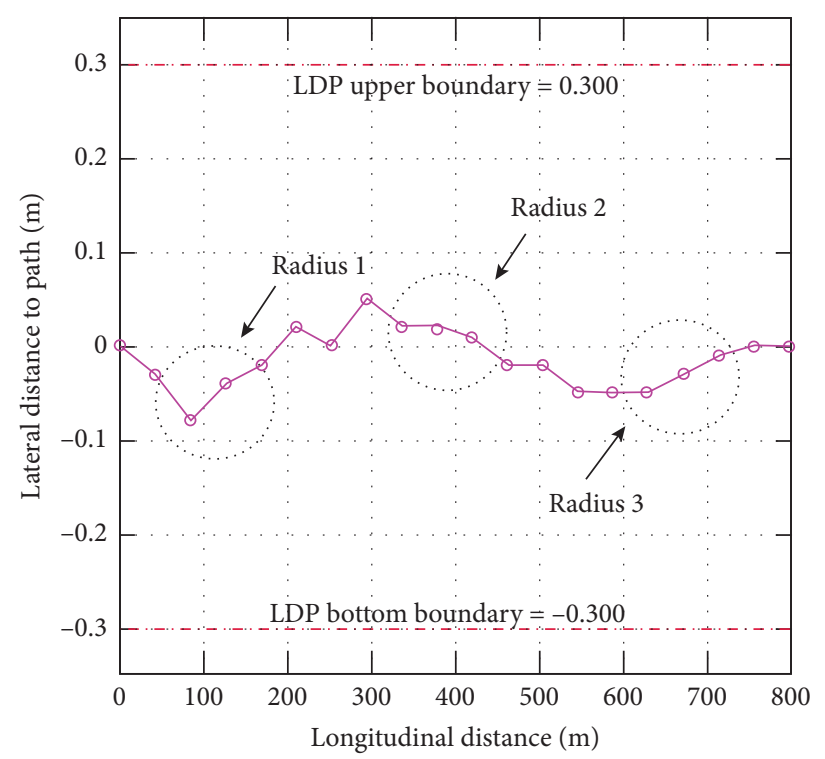

$\rightarrow$ LDP in section 4

(a)

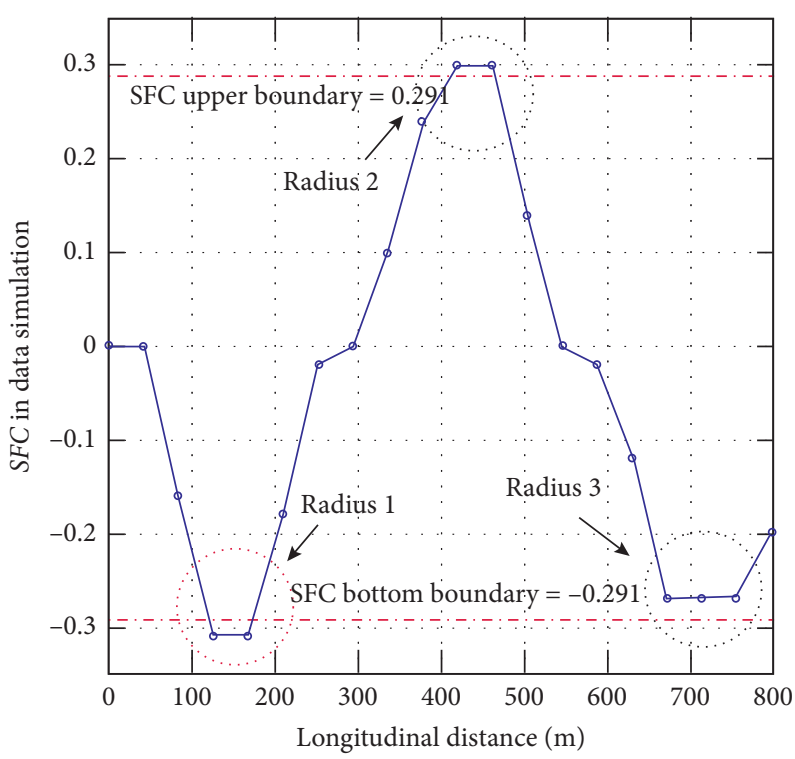

SFC in section4

FIgure 11: The simulation results of Section 4. (a) Lateral Distance Path Change Trend. (b) SFC Change Trend.

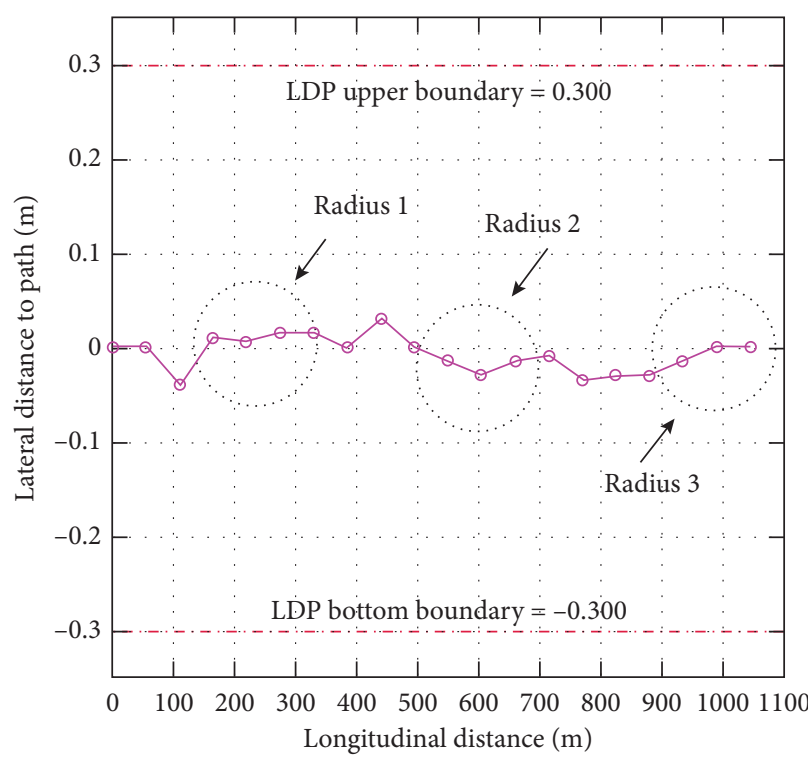

- - LDP in section5

(a)

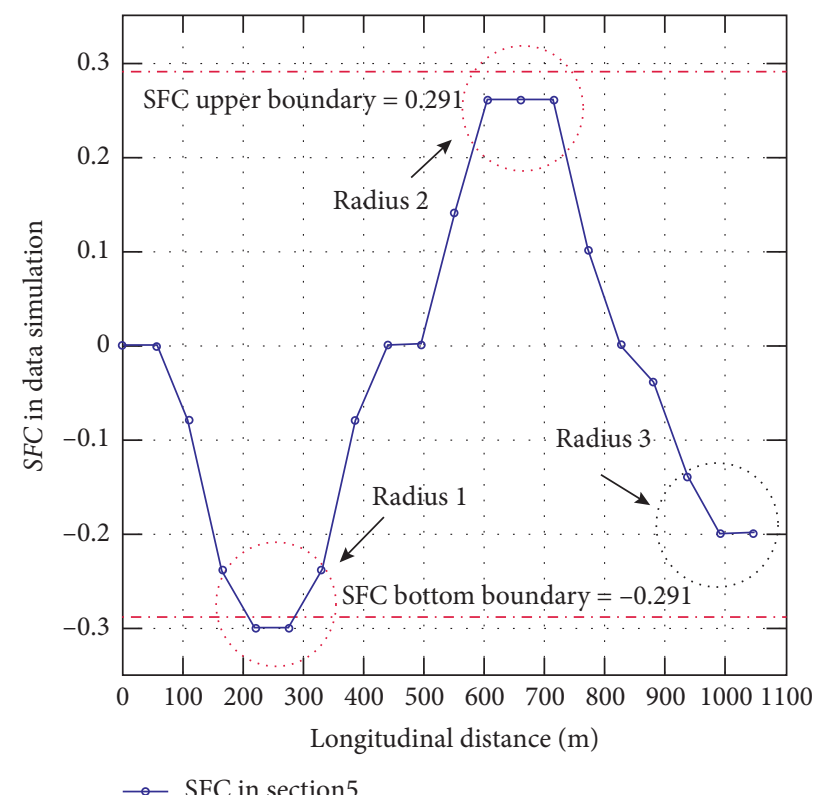

(b)

FIgURe 12: The simulation results of Section 5. (a) Lateral Distance Path Change Trend. (b) SFC Change Trend.

too large, owning to small value of superelevation angle. In current ISO standard [36], passengers' comfort was defined as index shown in Table 7. Moreover, the passengers' comfort was also specifically defined in China [27], also provided in Table 7. It could be directly concluded that Chinese passengers have significant stronger endurance. In related references, passengers' comfort was divided into several levels varying from not uncomfortable to extremely uncomfortable. $S F C_{c}$ obtained in this paper lies in the third level of China range, interpreted as fairly uncomfortable or a little uncomfortable. In ISO range, $S F C_{c}$ is more than extremely uncomfortable, which is inappropriate in China. The boundary of comfortable and uncomfortable in China range is 0.184 , which is less than $S F C_{c}$. This is because the samples used in this study were adopted in scenic roads. Considering the special environment and stronger data set, $S F C_{c}$ has more practicality in scenic road design. 
TABLE 7: Passengers' comfort index.

\begin{tabular}{lcc}
\hline ISO range & China range & Event description \\
\hline $\begin{array}{l}\text { Greater than } 0.229 \\
0.145-0.229\end{array}$ & Greater than 0.510 & $\begin{array}{c}\text { Extremely } \\
\text { uncomfortable } \\
\text { Very uncomfortable }\end{array}$ \\
\hline $0.092-0.145$ & $0.367-0.510$ & Uncomfortable \\
\hline $0.057-0.092$ & $0.184-0.367$ & $\begin{array}{c}\text { Fairly uncomfortable } \\
\text { A little uncomfortable }\end{array}$ \\
$0.032-0.057$ & Less than 0.184 & Not uncomfortable \\
\hline Less than 0.032 & &
\end{tabular}

In Section 4.2, 15 curves from 5 scenic roads were verified using passengers' comfort and safety criterion. As depicted in Section 4.2, safety condition could be easily satisfied, but passengers' comfort could not be satisfied in curves with small radius. The scenic roads in this study were chosen from nature reserves with superior scenic road systems, which mean limit radius is rarely found. In scenic roads with worse terrain conditions, the situation mentioned above will be more rigorous. It is known that passengers' comfort is related to operation velocity, curve radius, and superelevation. Therefore, to meet passengers' demand, scenic road design should take these three indicators as a whole based on $S F C_{c}$.

\section{Conclusions}

In this study, a new indicator SFC means passengers' comfort was introduced, which is different from lateral acceleration used in current criterions and related studies. Lateral acceleration could not fully represent the passengers' overload because human body is vertical to road surface. Thus, considering the superelevation, SFC could stand for real overload in a curve. Based on dynamic balance condition of the vehicle on horizontal curve, the derivation process of SFC was provided. Field tests on over 1000 participants were carried out in 5 different scenic road curves to investigate $S F C_{c}$ representing passengers' comfort tolerance limitation. To verify $S F C_{c}$ from the perspectives of both passengers' comfort and driving safety, numerical simulations of 15 horizontal curves from 5 scenic roads were also conducted. The value of $S F C_{c}$ was determined as 0.291 based on the statistical analysis on data obtained in field tests. The results also showed that age and gender have no effect on $\mathrm{SFC}_{c}$. Moreover, the corresponding minimum radius limits under $20-60 \mathrm{~km} / \mathrm{h}$ and superelevation $6 \%, 8 \%$, and $10 \%$ were proposed. The results of numerical simulations denoted two points. First, in current in-service scenic roads, there are curves that could not satisfy the passengers' comfort demand, which showed that finding an appropriate way promoting passengers' comfort in scenic road is promising. Second, when passengers' comfort demand $S F C_{c}$ is satisfied, the safe driving requirements could also be satisfied. Therefore, $S F C_{c}$ and minimum radius limits proposed in this study were proved to be credible and appropriate for the curve design of horizontal alignment in scenic roads.
This study also has a shortage. Field tests were carried out in Xi'an, whose terrain is relatively flat. That means citizens in this city might have higher comfort demand in daily commute and recreation travel, compared to citizens living in mountainous and hilly areas. Therefore, values of $S F C_{c}$ determined in different areas may vary. The following researches will focus on this issue, providing more practical values of $S F C_{c}$ in different areas by enlarging the investigation scope.

\section{Data Availability}

The data used to support the findings of this study are available from the corresponding author upon request.

\section{Conflicts of Interest}

The authors declare that there are no conflicts of interest regarding the publication of this paper.

\section{Acknowledgments}

This research was funded by National Key R\&D Program of China (Grants nos. 2018YFB1600302 and 2018YFB1600300) and supported by Science Foundation project of Chongqing Jiaotong University (Grant no. 20JDKJC-B001).

\section{References}

[1] National Park Service, Park Road Standards, National Park Service, Washington, DC, USA, 1968.

[2] American Association of State Highway and Transportation Officials, A Policy on Geometric Design of Highway and Streets, AASHTO, Washington, DC, USA, 1984.

[3] Transportation Research Board, Highway Capacity Manual, TRB, Washington, DC, USA, 5th edition, 2010.

[4] International Organization for Standardization, Mechanical Vibration and Shock-Human Exposure-Vocabulary, ISO, Geneva, Switzerland, 1997.

[5] K. Strandemar, On Objective Measures for Ride Comfort Evaluation, Royal Institute of Technology (KTH), Stockholm, Sweden, 2005.

[6] J. Forstberg, Ride Comfort and Motion Sickness in Tilting Trains, Royal Institute of Technology (KTH), Stockholm, Sweden, 2000.

[7] M. O. Rodrigues, An Evaluation of the Level of Service in the Public Transportation System of the City of Sao Carlos, Masters dissertation. University of Sao Paulo, Sao Carlos, Brazil, 2006.

[8] C. Y. Lin, L. J. Chen, Y. Y. Chen, and W. C. Lee, "A comfort measuring system for public transportation systems using participatory phone sensing," in Proceedings of Phone Sense 2010, Zurich, Switzerland, 2010.

[9] R. Alkhatib, G. Nakhaie Jazarb, and M. F. Golnaraghi, "Optimal design of passive linear suspension using genetic algorithm," Journal of Sound and Vibration, vol. 275, no. 3-5, pp. 665-691, 2004.

[10] D. V. Koulocheris, V. K. Dertimanis, and K. N. Spentzas, "Analysis and optimization of a fixed-tank vehicle," Forschung im Ingenieurwesen, vol. 70, no. 3, pp. 171-178, 2006.

[11] D. V. Koulocheris, V. K. Dertimanis, V. Spitas, and C. Spitas, "Heavy vehicle roll plane modeling and optimization of transmissibility ratios," in Proceedings of the 5th IC-SCCE, Athens, Greece, 2012. 
[12] D. V. Koulocheris, H. Vrazopoulos, and V. K. Dertimanis, "Optimization methodology for tuning fuzzy logic controllers," in Proceedings of the 15th IFAC Triennial World Congress. IFAC, Barcelona, Spain, 2002.

[13] W. Belgacem, A. Berry, and P. Masson, "Active vibration control on a quarter-car for cancellation of road noise disturbance," Journal of Sound and Vibration, vol. 331, no. 14, pp. 3240-3254, 2012.

[14] J. Meng, Q. Chen, and R. He, "Research on optimal control for the vehicle suspension based on the simulated annealing algorithm," Journal of Applied Mathematics, vol. 2014, pp. 1-5, Article ID 420719, 2014.

[15] M. Brogioli, M. Gobbi, G. Mastinu, and M. Pennati, "Parameter sensitivity analysis of a passenger/seat model for ride comfort assessment," Experimental Mechanics, vol. 51, no. 8, pp. 1237-1249, 2011.

[16] F. A. Joseph, J. C. Issac, and T. J. Paulson, "Low frequency vibration analysis on passenger car seats," International Journal of Scientific \& Engineering, vol. 4, no. 8, pp. 1-5, 2013.

[17] M. Demicd, J. Lukicd, and Z. Milicd, "Some aspects of the investigation of random vibration influence on ride comfort," Journal of Sound and Vibration, vol. 253, no. 1, pp. 109-128, 2002.

[18] S. Lerspalungsanti, A. Albers, S. Ott, and T. Düser, "Human ride comfort prediction of drive train using modeling method based on artificial neural networks," International Journal of Automotive Technology, vol. 16, no. 1, pp. 153-166, 2015.

[19] N. J. Mansfield and M. J. Griffin, "Deference thresholds for automobile seat vibration," Applied Ergonomics, vol. 31, no. 1, pp. 255-261, 2000.

[20] M. Kilic and S. M. Akyol, "Experimental investigation of thermal comfort and air quality in an automobile cabin during the cooling period," Heat and Mass Transfer, vol. 48, no. 8, pp. 1375-1384, 2012.

[21] M. J. M. Nor, M. Hosseini Fouladi, H. Nahvi, and A. Kamal Ariffin, "Index for vehicle acoustical comfort inside a passenger car," Applied Acoustics, vol. 69, no. 4, pp. 343-353, 2008.

[22] S. Cafiso and G. La Cava, "Driving performance, alignment consistency, and road safety," Transportation Research Record: Journal of the Transportation Research Board, vol. 2102, no. 1, pp. 1-8, 2009.

[23] J.-H. Lee, J.-J. Park, S. H. Park, and C. Baek, "Development of evaluation criteria for curve-section safety level with visual distortions on two-lane rural highways," KSCE Journal of Civil Engineering, vol. 20, no. 2, pp. 873-880, 2016.

[24] X. Wang, T. Wang, A. Tarko, and P. J. Tremont, "The influence of combined alignments on lateral acceleration on mountainous freeways: A driving simulator study," Accident Analysis \& Prevention, vol. 76, no. 3, pp. 110-117, 2015.

[25] M. Nicke and W. Hugemann, "Longitudinal and lateral accelerations in normal day driving," in Proceedings of the ITAI Conference, the Institute of Traffic Accident Investigators, Croydon, England, 2003.

[26] A. Altamira, Y. Garcia, T. Echaveguren, and J. Marcet, "Acceleration and deceleration patterns on horizontal curves and their tangents on two-lane rural roads," in Proceedings of the TRB 93rd Annual Meeting, Washington DC, USA, 2014.

[27] J. Xu, K. Yang, Y. M. Shao, and G. Y. Lu, "An experimental study on lateral acceleration of cars in different environments in Sichuan, southwest China," Discrete Dynamics in Nature and Society, vol. 2015, Article ID 494130, 16 pages, 2015.

[28] R. A. Tokunaga, M. Asano, K. Munehiro, and T. Hagiwara, "Effects of curve designs and road conditions on driver's curve sharpness judgment and driving behavior," Journal of the Eastern Asia Society for Transportation Studies, vol. 6, pp. 3536-3550, 2005.

[29] J. C. Castellanos and F. Fruett, "Embedded system to evaluate the passenger comfort in public transportation based on dynamical vehicle behavior with user's feedback," Measurement, vol. 47, no. 1, pp. 442-451, 2014.

[30] F. Yakar and F. Celik, "A highway alignment determination model incorporating GIS and multi-criteria decision making," KSCE Journal of Civil Engineering, vol. 18, no. 6, pp. 18471857, 2014.

[31] P. Jia, L. J. Chu, and T. F. Fwa, "Determination of safe vehicle speeds on wet horizontal pavement curves," Road Materials and Pavement Design, vol. 21, no. 7, 2020.

[32] C. Zong and K. Guo, "Objective evaluation index for handling and stability of vehicle," Natural Science Journal of Jilin University of Technology, vol. 30, no. 1, pp. 1-6, 2000.

[33] Y. Guo, J. Wang, S. Peeta, and P. Anastasopoulos, "Personal and societal impacts of motorcycle ban policy on motorcyclists' home-to-work morning commute in China," Travel Behaviour and Society, vol. 19, pp. 137-150, 2020.

[34] Y. T. Guo and S. Peeta, "Impacts of personalized accessibility information on residential location choice and travel behavior," Travel Behaviour and Society, vol. 19, pp. 99-111, 2019.

[35] Y. Guo, J. Wang, S. Peeta, and P. Anastasopoulos, "Impacts of internal migration, household registration system, and family planning policy on travel mode choice in China," Travel Behaviour and Society, vol. 13, pp. 128-143, 2018.

[36] International Organization for Standardization, Mechanical Vibration and Shock-Evaluation of Human Exposure to Whole-Body Vibration-Part 1: General Requirements, ISO, Geneva, Switzerland, 1997. 